\title{
Showing or Telling a Story: A Comparative Study of Public Education Texts in Multimodality and Monomodality
}

\author{
Kelu Wang ${ }^{1}$ \\ ${ }^{1}$ School of Foreign Languages, Leshan Normal University, Sichuan, China \\ Correspondence: Kelu Wang, School of Foreign Languages, Leshan Normal University, No. 778 Binhe Road, \\ Leshan City, Sichuan Province, China. Tel: 86-151-8227-5027. E-mail: kelu207@hotmail.com
}

The research is financed by the Teaching Reform Project of Leshan Normal University (JG11-YB10)

Received: December 10, 2012 Accepted: December 21, 2012 Online Published: January 9, 2013

doi:10.5539/elt.v6n2p136 URL: http://dx.doi.org/10.5539/elt.v6n2p136

\begin{abstract}
Multimodal texts that combine words and images produce meaning in a different way from monomodal texts that rely on words. They differ not only in representing the subject matter, but also constructing relationships between text producers and text receivers. This article uses two multimodal texts and one monomodal written text as samples, which are for the same purpose of public education and on the same subject matter of wildlife protection. Through a comparative analysis of the two sets of sample texts, this article aims to show that different modes of representation produce different effects on text receivers and convey different amount of information. Thus, the multimodal texts and monomodal texts can meet the needs of different readers, who want to know about a subject matter or seek for detailed information on that subject matter. In addition, the different ways of meaning representation requires different modes of reading for readers of multimodal texts and monomodal texts.
\end{abstract}

Keywords: multimodal, monomodal, comparative analysis, subject matter, interpersonal relationships

\section{Introduction: Objectives and Theoretical Framework}

Multimodality (writing and image) and monomodality (writing) produce different effects on readers, and demand different modes of reading. Readers approach multimodal texts and monomodal texts for different purposes. Through a comparative analysis of multimodal texts and a monomodal text that are on the same subject matter, this article shows that multimodal texts utilizing the affordances of writing and image are more effective in attracting viewers' attention and delivering the message in a split second, while the monomodal text of writing is more effective in providing readers with detailed information of the subject matter. Reading the written text is thereby often motivated by seeing the multimodal texts in advance. Moreover, since multimodal texts do not display as much detailed information as the written text does, they allow viewers more involvement in co-constructing the meaning of the texts; whereas, the written text gives readers more information and often controls the direction of reading. The different ways of meaning representation require different modes of reading for readers of the multimodal texts and written text.

The multimodal texts Homeless Penguins (http://adsoftheworld.com/media/print/wwf_homeless_penguin) and Homeless Polar Bears (http://adsoftheworld.com/media/print/wwf_homeless_polar_bear) used in this comparative study are campaign materials created by World Wildlife Fund (WWF), in which written and visual elements are integrated in a compositional whole to warn viewers the horrendous future faced by polar bears and penguins if global warming continues. The monomodal text is a piece of writing published online entitled Climate Change Could Harm Penguins and Polar Bears ( http://www.usnews.com/news/energy/articles/2009/03/23/climate-change-could-harm-penguins-and-polar-bears ), which introduces severe consequences for polar bears and penguins brought about by climate change. Both the campaign materials and writing are on the same subject matter of wildlife protection, and for the same purpose of educating people of the harmful effects of climate change on polar bears and penguins, and advocating people to protect environment and stop the current situation getting worse.

The comparative analysis draws on Halliday's (1994) notion of metafunctions as the theoretical framework. 
Linguistic system has three metafunctions: ideational, interpersonal and textual metafunction. The ideational metafunction focuses on the content or knowledge of the world represented in language. The interpersonal metafunction refers to the relationships constructed by participants through language. And the textual metafunction deals with the ways texts are structured and composed. The analysis compares how texts of different modes present the subject matter and create interpersonal relationship through linguistic and visual features.

This article first analyzes the structure of the multimodal texts and the thematic participants in the written text, displaying the first impression respectively created by the campaign materials and writing. Then it examines the events and circumstances depicted in the multimodal texts and the transitivity aspects of the written text, showing the difference in meaning construction between multimodality and monomodality. Next, the article explores how the viewer of the multimodal texts is "shown" (Bearne, 2005, p. 20) and how the reader of the written text is "told about" (Bearne, 2005, p. 20) the relationships between climate change and animals with linguistic and visual features. Finally, it demonstrates how the two texts respectively position readers with a combination of linguistic and visual features and linguistic features.

\section{Public Education Texts: First Impressions}

The multimodal texts and monomodal written text use different resources to present the same subject matter at viewers'/readers' first impression. Multimodal texts combining both writing and visual image could relate words with images and highlight certain elements to draw viewers' attention, while the choice of thematic participants contributes to the overall sense of what a written text is about (Droga \& Humphrey, 2003).

\subsection{The Structure of the Multimodal Texts}

The structure and organization of the multimodal texts directly display the primary concern or subject matter at viewers' first impression. The polar bear or penguins are placed in the near-central position in the pictures. The slogans You can help and Stop global warming are printed in striking color and big case against the dark background. And the words stop and global warming are separated by frame. This center-periphery arrangement of space (Bearne \& Kress, 2001) and the use of color and frame make the objects (animals) and concept (global warming) salient to viewers, and help them to recognize the subject matter - the harmful effects of climate change on polar bears and penguins at the very moment when they see the texts.

\subsection{Thematic Participants in the Written Text}

In the written text, it is thematic participants that reflect its principal concern (Moore, 2010). Thematic participants are "those participants occurring in subject position in a clause" (Halliday, 1994, p. 58) and a thematic participant is usually what "a clause is principally concerned" (Halliday, 1994, p. 58). A quick glance at the thematic participants would give readers a brief view of the main content of the written text.

Polar bears and penguins and expressions related with them appear most often in the theme position. A summary of these thematic participants are categorized as follows: (1) Polar bears and penguins appear in the theme position side by side using expressions like polar bears and penguins, penguins and polar bears, these already highly adapted animals; polar bears are talkedin polar bears, bears, female polar bears or the great while mammals; specific species of penguins are mentioned with the emperors, the emperor penguins, the best-known penguin varieties, Antarctic penguins,Adélie chicks, young penguins are referred to as newborn and very young chicks. (2) Pronouns they, some and others are used to refer to polar bears or penguins. (3) Other expressions related to the life of polar bears and penguins are also used as themes in the written text, including their well-being, the population growth, the populations, polar bear and penguin populations and these animal habitats. The alternative use of direct naming polar bears and penguins and other expressions related to them as themes indicate that the major concern of the written text is the two animals, and the knowledge about them.

Expressions of climate change appear less often than polar bears and penguins, but still occupy many theme positions throughout the written text. These expressions can be divided into three kinds: (1) General expressions such as climate change, these changes, these trends, the long-term trend, that course, and the problems the penguins and the polar bears face at the extremes of the world; (2) expressions aboutthe temperature aspect of climate change, such as air temperatures, warming temperatures, warming air temperatures, global temperature; (3) Ice melting resulted from climate change is stated with expressions like ice, periods of reduce sea ice, the amount of ice, scare ice, Arctic sea ice, less multiyear ice, less sea ice, the remaining ice, rain, and increased rain. The large number of expressions of climate change, in general and specific terms, suggests that the other focus of the written text is climate change and its manifestations. Readers might automatically establish a connection between the two most frequent thematic participants - animals and climate change, and perceive the 
subject matter. Taking a look at the thematic participants throughout the written text makes it easy for readers to get the subject matter as they skim through the text.

\section{Patterns of Transitivity: Events and Circumstances}

The multimodal texts and monomodal written text not only have distinctively different ways to create first impressions upon the subject matter, but also differ in constructing meanings on the subject matter due to their different affordances. The affordance of a particular mode means what it is possible or not possible to do with that particular mode (Bearne \& Kress, 2001). The affordance of visual image lends itself well to the display of salient elements and their relation, while the affordance of writing does good to representation of a sequence of events happening in time (Bearne \& Kress, 2001). Image displays what an object look like, "and writing describes events - what has happened, what is about to happen, etc." (Berne \& Kress, 2001, p. 91). As to the multimodal texts and written text under discussion in this article, the former display a fictional world that symbolizes the dire future polar bears and penguins might face, and the latter tells a story that gradually unfolds a series of events that lie behind the effects of climate change on polar bears and penguins. An analysis of the events and circumstances helps viewers understand the world represented in the multimodal texts, and a transitivity analysis probes into the events and circumstances embedded in the written text. This kind of comparative analysis with relevant visual and linguistic features will explain the different reasons for reading.

\subsection{The Events and Circumstances in the Multimodal Texts}

Multimodal texts with image and words have limited capability of providing detailed information. There are a series of events lying behind the scene displayed in the texts and being constructed by conceptual images that set out a range of related objects (Bearne\& Kress, 2001). An attempt to relate these objects and make appropriate inferences helps to describe the events and interpret the meaning encoded in multimodal texts.

In the polar bear text, one polar bear is sitting on the edge of the street leaning against the wall, like a hungry homeless tramp. He seems to be looking at one of his paws, thinking about something. At the far end of the street, there are a line of trash bins, one of whose cover is half open. A similar scene is displayed in the penguin text in which a penguin and her baby are shivering close to a burning barrel on the deserted street, looking lonely and helpless. The incongruence between animals and their usual pristine habitat being replaced by polluted backstreet city environment creates a shocking value. Looking at these texts, one would naturally relate those objects and make appropriate inferences. They possibly will come up with a series of questions: Why do the polar bear and penguins leave their own habitats and show up in a city? Why is the polar bear gazing at his paw? Is that because he just scavenges for food in the trash bins? Why do the penguins stand by the fire? Shouldn't they prefer coldness? What pushes polar bears and penguins to such a terrible world? When the highlighted words global warminggreet readers' eyes, readers relate them to the events described in the texts, and make speculation that global warming is the cause. And this speculation could soon be verified when viewers move their eyes down to the bottom of the text where a sentence in small size states that Animals around the world are losing their habitats due to climate change. The conjunction due to clearly points out that global warming is responsible for everything happens in the texts. At this moment, when all the objects and concepts are related and reasonable explanation is formed, the meaning of the texts is partially successfully constructed. The multimodal texts are effective in making salient the images of animals and the concept of global warming, and helping establish a relation between these salient elements. In this sense, the multimodal texts are more likely to catch readers' attention and awaken their awareness of the problem, make them ponder and encourage them to do more reading because those questions lingering in their mind cannot be answered by the information reflected in the multimodal texts.

Circumstances in the multimodal texts play a significant role in foregrounding the gloomy prospect for polar bears and penguins. The surroundings in which polar bears and penguins appear are filthy and messy. In the polar bear text, the road is broken with puddles here and there; waste papers, a tin and an old checkered blanket are casually littered; the building looks shabby and lifeless; the wall is scrawled and peeling; the wires are twined together. Similar surroundings are described in the penguin text. The image of the multimodal texts creates a forlorn and bleak world as if abandoned by human beings. It makes viewers wonder how the world could become this desolate and decayed, whether the effects of global warming on animals can be this serious, and how soon this will happen. By asking these questions, viewers have been stimulated to think beyond what they see on pictures and prepared for more readings. So circumstances here contribute to the representation of the world, and help construct the meanings on the subject matter as well - the harmful effect of global warming on polar bears and penguins. Otherwise, they will have to visualize those circumstances on their own, since words are often less precise than images. 


\subsection{Transitivity Analysis of the Written Text}

Unlike the multimodal texts which create a shocking and inspiring effect on readers, the written text delivers a large amount of information, including a series of events, the circumstances of these happenings, causes and effects of climate change on polar bears and penguins. A transitivity analysis that analyzes "the components of language that function to represent "who does what, to whom, where, when, and how" helps reveal "how the world is represented" (Coffin, Donohue \& North, 2009, p. 288) in the multimodal texts. Process, participant, and circumstance are referred to as transitivity system (Ravelli, 2000). Process is about the action or events presented in the clause; participant shows who are involved in the event or situation; and circumstance usually tells where, when, why and how is the event occurring (Coffin, Donohue \& North, 2009). In combination, process, participant, and circumstance are key components for readers "to build a mental picture of reality" (Halliday, 1994, p. 107).

The following paragraph taken from the written text introduces the current living conditions of polar bears and penguins. The description coincidentally matches very well with the events presented in the multimodal texts.

In the Arctic, hungry polar bears, unable to sustain themselves on the melting ice, are increasingly making their way inland to such towns as Noorvik, Alaska, and Churchill, Manitoba, where they sniff out garbage bins and scavenge for dinner. And in the Antarctic, wet baby penguin chicks shiver in the rain; warming temperatures mean less snow but more rain, which soaks them through, putting them at risk of freezing to death. (http://www.usnews.com/news/energy/articles/2009/03/23/climate-change-could-harm-penguins-and-polar-bears)

Transitivity analysis of this paragraph, as shown in Table 1, presents some events hidden behind the multimodal texts. It not only shows the difficult situation confronted by polar bears and penguins, but also indicates the location of the events.

Table 1 . The transitivity analysis

\begin{tabular}{|c|c|c|c|c|c|}
\hline Clause & Circumstance & Participant & Process & Participant & Circumstance \\
\hline $\mathrm{a}$ & In the Arctic & $\begin{array}{l}\text { hungry polar } \\
\text { bears }\end{array}$ & $\begin{array}{l}\text { unable } \\
\text { sustain }\end{array}$ & themselves & on the melting ice \\
\hline b & & & $\begin{array}{l}\text { are } \\
\text { increasingly } \\
\text { making }\end{array}$ & their way & $\begin{array}{l}\text { inland to such towns as } \\
\text { Noorvik, Alaska, and } \\
\text { Churchill, Manitoba, }\end{array}$ \\
\hline c & where & they & sniff out & garbage bins & \\
\hline d & & & $\begin{array}{l}\text { and scavenge } \\
\text { for }\end{array}$ & dinner. & \\
\hline $\mathrm{e}$ & $\begin{array}{l}\text { And in } \\
\text { Antarctic }\end{array}$ & $\begin{array}{l}\text { wet baby } \\
\text { penguin chicks }\end{array}$ & shiver & & in the rain; \\
\hline f & & $\begin{array}{l}\text { warming } \\
\text { temperatures }\end{array}$ & mean & $\begin{array}{l}\text { less snow but } \\
\text { more rain, }\end{array}$ & \\
\hline $\mathrm{g}$ & & which & soaks & them & Through, \\
\hline $\mathrm{h}$ & & & putting & them & $\begin{array}{l}\text { at risk of freezing to } \\
\text { death }\end{array}$ \\
\hline
\end{tabular}

At clause (a), polar bears are involved in the event of being unable to sustain themselves, and the two circumstances indicate that this happens on the melting ice in the Arctic. Clause (b) presents another important event that polar bears are moving, and the circumstance here explicitly points out that the destination of their move is human-occupied areas such as Noorvik, Alaska, and Churchill and Manitoba. Then clause (c) and (d) present two actions of polar bears - sniffing out garbage bins and scavenging for dinner. A careful analysis of clauses (e) to (h) in this way reveals that penguins are involved in the events of being soaked through by rain, shivering in the rain, and being put into the danger of freezing to death. These words describe a sequence of events that might have happened before what is represented in the multimodal texts, and give a bit explanation to the questions like why polar bears leave their original habitats, and why penguins stand so close to the fire. If readers have seen the multimodal texts, they will immediately associate these sentences with those images kept in their mind, and realize that the terrible future for polar bears and penguins depicted in the multimodal texts might not be fictional, and something like that is happening in reality.

Even though "circumstances are less central to the meaning of the events" (Coffin, Donohue \& North, 2009, p. 297) in the transitivity analysis, they play a critical part in showing the severity of climate change in the written text. The two passages below from the written text are scientists' prediction of the continuous effects of climate 
change on polar bears and penguins. A close examination of the circumstances shows that the written text gives much more details than the multimodal texts, so that it can meet the needs of those readers who want specific knowledge of this subject matter.

(a) Climate change models predict that, as global temperatures rise, periods of reduced sea ice will occur more frequently. Scientists say the amount of ice will still vary because climate change doesn't happen all at once, but the long-term trend points to less and less ice overall. If there are more frequent episodes of reduced ice, polar bear and penguin populations "can't recover in between bad years, so they end up declining over time," says Caswell. That is why the 3,000 breeding pairs of emperor penguins who inhabit Terre Adélie today are projected to decline to 400 breeding pairs by the end of the century. (http://www.usnews.com/news/energy/articles/2009/03/23/climate-change-could-harm-penguins-and-polar-bears)

In passage (a), circumstance of frequency frequently highlights that global warming would rapidly reduce the amount of sea ice. Then circumstances of time all at once, in between bad years, and over time help to point outthat the harm on polar bears and penguins is slow but almost irreversible. In the last sentence, another circumstance of time by the end of the century clearly indicates the severity of the effect of climate change on the animals by making prediction on the moment when the emperor penguin population would drop to a pitifully small number.

(b) In Canada's Hudson Bay area, which includes Churchill (nicknamed "the polar bear capital of the world"), there are 25 percent fewer polar bears than 25 years ago. On the Antarctic Peninsula, where air temperatures have warmed about 5 degrees Fahrenheitin the past 50 years, Adélie penguins have declined by 65 percent, and the emperor also penguins are in peril. (http://www.usnews.com/news/energy/articles/2009/03/23/climate-change-could-harm-penguins-and-polar-bears)

In passage (b), two circumstances of space in Canada's Hudson Bay area and On the Antarctic Peninsula make it clear where these events happen. Then the circumstances than 25 years ago, about 5 degrees Fahrenheit, in the past 50 years and by 65 percent introduce statistics to demonstrate the sharp shrinkage of polar bears and penguins, thus raising readers' awareness of the terribly harmful effects that climate change has done on polar bears and penguins.

The multimodal texts capture only an instance in displaying the world, and the story behind that moment relies on readers' inferences; whereas, the written text tells a story through a series of events over time and the precise description of circumstantial details. The multimodal texts, assisted by image that is visually vivid and impressive when representing the world, are better at invoking viewers' curiosity and motivating them to know more about polar bears and penguins from the written text.

\section{Contrasting Discourse Markers: The Relationships between Climate Change and Polar Bears and Penguins}

When it comes to emphasizing the harmful effect of climate change on polar bears and penguins, both the writing in the multimodal texts and monomodal written text use conjunctions to express the relation of cause. But there is also difference: The multimodal texts show the relationships through "the placing of images in space" (Bearne, 2005, p. 20), displaying the miserable fate of animals in front of readers; the written text tells the relationships through "a sequence of sentences" (Bearne, 2005, p. 20), using conjunctions and clause-combining strategies to emphasize the negative effect,.

\subsection{The Combination of Image and Writing in the Multimodal Text}

As what has been discussed before, in the multimodal texts the causal relation between global warming and the horrible future for animals is achieved in two aspects: on the one hand, the salient images of animals and landscape and the words global warming help viewers establish a relation between them; the conjunction due to in the writing Animals around the world are losing their habitats due to climate change explicitly manifests this causal relation. In a word, image and writing are combined for an understanding of the causal relation in the multimodal texts.

\subsection{Conjunctions and Clause-combining Strategies in the Written Text}

The written text depends on linguistic features like conjunctions and clause-combining strategies to show the relationships between climate change and the fate of polar bears and penguins. More importantly, how climate change harms these animals is clearly presented to readers. The following sentences are taken from the written text. Sentences (a), (b) and (c) introduced by the conditional conjunction if state that the rising air temperature is the condition for the serious consequence of polar bear population decreasing and penguins dying. While it is much more difficult to communicate conditional relationship with visual devices, if in the written text can signal 
to what extent the information about the future is at this moment still conditional.

(a) If there are more frequent episodes of reduced ice, polar bear and penguin populations "can't recover in between bad years, so they end up declining over time, "says Caswell.

(b) If the ice breaks up too soon and the chicks fall into the water, they will not survive because their outer coats are not yet waterproof, Boersma says.

(c) If the scientists are right, that course could lead to severe consequences for humans as well as penguins and polar bears.

(http://www.usnews.com/news/energy/articles/2009/03/23/climate-change-could-harm-penguins-and-polar-bears)

At sentence (d), conjunction and links one clause about the fact that warming air temperatures have led to more rain, with the other clause about the harm of rain on penguins. The and does not establish a relation of cause, but it helps readers relate the rising temperature to the harmful effects on animals.

(d) In the Western Antarctic Peninsula, warming air temperatures (the 6-degree rise over the past 50 years is the largest increase in the world) have led to more precipitation in the form of rain, rather than snow, and that spells trouble for Adélie penguins and their chicks. (http://www.usnews.com/news/energy/articles/2009/03/23/climate-change-could-harm-penguins-and-polar-bears)

When and with are respectively used in sentence (e) and (f) to introduce the clause describing the phenomenon of ice decreasing. When suggests that a sequence of happenings, that is to say, the Adélie penguin population becomes smaller sequentially after the sea ice decreases, thus ithelps establish a causal relationship between climate change and the number of penguins. And with introduces the reason that causes a series of damage done to polar bears.

(e) We found evidence that the population growth was negatively impacted when there were periods of decreasing sea ice.

(f) At the same time, with ice forming later each fall and breaking up earlier each spring, female polar bears have less time to feed and store up fat that will allow them to sustain pregnancies and then nurse and care for their cubs long enough for them to survive.

(http://www.usnews.com/news/energy/articles/2009/03/23/climate-change-could-harm-penguins-and-polar-bears)

Conjunctions and clause-combining strategies in the written text directly connect the specific phenomena of climate change with polar bears or penguins, making readers clearly know how the warming temperature or the reduced sea ice results in the decreasing population of polar bears and penguins.

The above comparison of the devices used for introducing relationships in the multimodal texts and written text reveals that the written text can not only explicitly tell the relation of cause-and-effect but also provide detailed information about the causes, which is hardly achieved by the simple writing and image in the multimodal text under discussion. The need for more information becomes one of the reason why viewers may choose to read if they come across the multimodal texts.

\section{Modes of Address: Constructing Textual Designers/Writers and Viewers/Readers}

Text producers"demonstrate their understanding of the role relationships inherent in each context and express their stance toward the texts they are creating" through deliberate choices of interpersonal components (Schleppegrell, 2004, p. 58). Different interpersonal components used in the multimodal texts and written text allow viewers/readers more or less agency in constructing the meaning of the texts, and create different interpersonal relationships between the designer/writer and the viewer/reader. Therefore, image and writing in the multimodal texts and mere writing in the written texts offer viewers/readers different modes of perceiving and apprehending the texts.

\subsection{Mood, Shot Type, Visual Modality, and Perspective in the Multimodal Texts}

The interpersonal relationship in the multimodal texts is realized by mood, shot type, visual modality, and perspective (Stenglin\&Iedema, 2001). Mood in images means whether the subjects enter into direct eye-contact with the viewer. The differences in shot depend on the distance of shot. Modality in visuals, consisting of color and focus, "realizes what 'we' consider true or less true" (Stenglin\&Iedema, 2001, p. 202). And perspective is the angle of looking at objects, and different perspectives stand for different degrees of social involvement (Stenglin\&Iedema, 2001).

The designer of the multimodal texts deliberately selected and displayed a moment of climax that impacts a series of events behind it. This moment is shocking enough not only to awaken viewers' awareness of the 
harmful effects of climate change on polar bears and penguins, but to urge them to take actions to protect the environment and save the animals from the awkward situation.

In the multimodal texts, neither the polar bears nor the penguins have eye contact with viewers. The polar bear is gazing at his paw, and the penguins are looking at the fire. The absence of eye-contact with viewers makes the multimodal texts "'offer' themselves for a less engaged and more objective kind of observation" (Stenglin\&Iedema, 2001, p. 202). So when people watch these texts, they are less likely to have a sense of involvement, but observe what is happening there as an outsider.

The polar bears and penguins are captured with a medium long shot that cut off their full figures. Medium long shot suggests viewers have "a public acquaintance" (Stenglin\&Iedema, 2001, p. 202) with polar bears and penguins that are portrayed in the multimodal texts. That is to say, they are not involved in viewers' private life but part of their public concern. Even if they don't know much about polar bears and penguins, most viewers have certain amount of knowledge that enables them to get the specialty and significance of the animals being put in an environment that they do not feature.

The primary colors of the multimodal texts are black and white. Besides the polar bear and penguins that are naturally in black and white, the whole background is colored in black and white. Only the trash bins in the polar bear text, the barrel and fire in the penguin text, and the slogans in both texts are colored. This is highly possible for the purpose of drawing viewers' attention and encouraging them to establish connection between objects and make inference. With appropriate amount of details being provided, both texts look like photos, thus give readers a feeling that what is portrayed is real in life. It is likely that viewers will be promoted to see how "true" it is through their own reading after coming across the multimodal texts somewhere.

The polar bear and penguins are positioned at the same level with viewers, which suggests that they are treated equally to human beings. This horizontal angle is better at putting viewers in the position of animals, so that they can realize the severity of the impact of climate change on animals.

Mood of the writing in the multimodal texts is also a resource for establishing interpersonal relationship. But totally different from mood in visual image, the mood in writing refers to grammatical choices to realize particular speech function. To be specific, "English has three mood options - declarative, interrogative, or imperative" (Schleppegrell, 2004, p. 58) that are respectively used to realize the function of statement, question or command. And "each choice suggests a different relationship between speaker/listener or writer/reader" (Schleppegrell, 2004, p. 58). The designer attributes quite a bit of power and agency to viewers, as they are portrayed as being able to stem the tide of destruction. For example, the imperative mood Stop global warming, and two examples sentences of declarative mood You can help (that is actually a request "help") and By recycling glass, plastic, cardboard and paper, you can help prevent this grant viewers trust and agency in changing the current situation.

\subsection{Mood and Modality in the Written Text}

Declarative mood is used throughout the written text to give readers information. It indicates that the writer is "claiming higher status or expertise than the reader, setting themselves up as an 'authority" (Goatly, 2000, p. 90) on the subject matter. This is possibly because the writer has done some research, which is evidenced by the use of data and quotations from scientists. For example, in the sentence But over the past 30 years, Arctic sea ice has diminished, with the National Snow and Ice Data Center reporting that 2008 could represent the lowest volume of Arctic sea ice on record, partly because less multiyear ice is surviving now, and the remaining ice is so thin. (http://www.usnews.com/news/energy/articles/2009/03/23/climate-change-could-harm-penguins-and-polar-bears), declarative mood is used to give readers the factual information that Arctic sea ice has diminished. Data and report from the authoritative department help increase the reliability of the information and enhance the writer's authority. When giving information, the writer carefully weighs the certainty of his/her statements and the strength of his/her claim with modality.

Modality is a resource for indicating the strength of one's opinion (Ravelli, 2004). It includes modal verbs and adjuncts which "enable the expression of interpersonal meanings that construe the stance of the speaker/writer" (Schleppegrell, 2004, p. 60). Two example sentences from the written text, though far less than enough, could still give some clues about the interpersonal relationship set up with readers.

(a) If they endure at all, some scientists suggest, it may be by interbreeding with brown bears and eventually evolving back into brown bears - the species scientists believe polar bears evolved from.

(b) Some scientists say that the problems the penguins and the polar bears face at the extremes of the world may serve as a preview of what will happen to the rest of the planet and all other species, including humans. 
(http://www.usnews.com/news/energy/articles/2009/03/23/climate-change-could-harm-penguins-and-polar-bears)

At sentence (a), qualifier some helps the writer defend for himself by admitting that not all scientists' views are considered here if there is an opposite opinion coming out. Then the modal verb can further decreases the strength of the writer's statement by suggesting that interbreeding is just one of many possibilities that will happen to polar bears. At (b), some and may achieve similar effect as at (a) to make the statements less dogmatic, but another qualifier all reassure readers the writer's certainty on this issue. In the written text, more modal verbs like could, will, can, likely and other modifiers like most and no are used to reduce the strength of the writer's claims. However, scientific texts like this one, using modality to reduce the degree of certainty and strength does not diminish the writer's authority because they are "self-assured enough to be cautious" (Goatly, 2000, p. 93) in stating their opinion.

\subsection{Evaluative Vocabulary and Intensifiers in the Written Text}

People use resources of appraisal to create particular interpersonal relationships by showing attitudes towards things, and describing how strong or weak these attitudes are. The resources of appraisal include evaluative vocabulary and graduation devices. Writers use evaluative vocabulary "in order to make positive and negative evaluations of a range of phenomenon" (Droga\& Humphries, 2003, p. 64), and graduation devices to intensify or quantify the forcefulness of the attitudes. Evaluative vocabulary is divided into three categories: Affect (expressing feelings), Judgment (evaluating behavior or character of people), and Appreciation (assessing the value of things). By using these appraisal resources, the writer is able to position readers at certain stance in understanding the subject matter presented to them.

The following sentences taken from the written text use evaluative vocabulary of Appreciation to describe polar bears and penguins. They create the image of polar bears and penguins as victims for the purpose of obtaining people's empathy towards these animals.

(a) In the Arctic, hungry polar bears, unable to sustain themselves on the melting ice, are increasingly making their way inland to such towns as Noorvik, Alaska, and Churchill, Manitoba, where they sniff out garbage bins and scavenge for dinner.

(b) With seal hunting moredifficult, bears search for other options.

(c) Nor is life likely to get easier for penguins, says Boersma, who has studied penguins for nearly 40 years.

(d) Moreover, she argues that these already highlyadapted animals cannot evolve as rapidly as current climate change models would require.

(http://www.usnews.com/news/energy/articles/2009/03/23/climate-change-could-harm-penguins-and-polar-bears)

At (a), polar bears are described to be suffering from hunger with the word hungry; at (b) the reason why polar bears are in hunger is related to the deteriorated situation of seal hunting, with the serious situation being described as difficult and intensified by more. At (c), when used together with the negation not, the word easier helps to make an evaluation of the bad living conditions for penguins. The modifier highly and the word adapted make a positive evaluation of the animals, and further indicate that even animals with strong adaptability have suffered from climate change.

The following sentences (e) to (i) use various evaluative words to show the harmful effects of climate change.

(e) And these changes could have dire consequences for the penguins and polar bears that inhabit those areas.

(f) "We found evidence that the population growth was negatively impacted when there were periods of decreasing sea ice," Caswell says. "The populations did not do as well."

..., and the remaining ice is sothin.

(g) "To me, there are two possible catastrophic circumstances that climate change could lead to," says Edmond Mathez.

(h) If the scientists are right, that course could lead to severe consequences for humans as well as penguins and polar bears.

(i) "We don't actually know what the future will bring, we should think of continuing on the same course as being very risky," Mathez says.

(http://www.usnews.com/news/energy/articles/2009/03/23/climate-change-could-harm-penguins-and-polar-bears)

Dire, catastrophic, severe, and risky are all negative vocabulary. Using them alternatively in the written text, the writer shows his/her negative attitudes towards climate change. At sentence (j), the only evaluative vocabulary of 
Affect optimistic is used to express the scientists' worry about polar bears' future. And then the evaluative word of Appreciation bright, which is intensified by very, is used with the negative word not to reiterate the worry held by scientists.

(j) If these trends continue, scientists aren't optimistic about polar bears' long-term viability. "Polar bears don't have a verybright future," says Michael Oppenheimer, a professor of geosciences and international affairs at Princeton University.

(http://www.usnews.com/news/energy/articles/2009/03/23/climate-change-could-harm-penguins-and-polar-bears)

What is noticeable in these sentences is that the writer expresses his attitudes in a very subtle way: Without showing his/her attitudes blatantly, the writer often quotes authoritative persons' words to support his/her own stance. For instance, the evaluation in sentence (c), (d), (f), (g), (i) and (f) are all made by scientists. Even if the writer seems to be invisible from making evaluation, his/her stance is still traceable from these evaluative vocabulary and intensifiers. By using these linguistic resources, the writer leads readers to take the stance of being alert to harmful effects of climate change on animals, and being willing to take actions to mitigate these effects.

\section{Conclusion}

The comparison of the two sets of public education texts shows that the affordance of image and writing respectively allows multimodal texts and monomodal text different effects on viewers'/readers' perceptions and understanding of the subject matter, creates different designer/writer-viewer/reader relationships, and makes viewers/readers take particular stance towards the subject matter.

With regard to the perceptions of the two sets of texts, the salient elements of the image and writing in the multimodal texts enable viewers to recognize the subject matter, while thematic participants in the written text help readers get the subject matter. As to the understanding of the subject matter, the multimodal campaign materials offer limited information but are more likely to arouse viewers' interest and concern. In the meantime, the monomodal written text is capable of giving a whole story of the events and circumstances, causes and effects related to the subject matter. Thus, an encounter with the campaign materials may motivate the viewers to read the essay on the same subject matter for a comprehensive and profound understanding.

Besides providing different means to perceive and understand the subject matter, multimodality and monomodality create different interpersonal relationships between designers/writer and viewers/readers, getting viewers/readers more or less involved into the meaning construction. For viewers, they are allowed to be more interactive with the texts, combing the image and writing to have a joint and coherent understanding of the subject matter; for readers, they are more directed by the writer to get information and knowledge from the text.

\section{References}

Bearne, E. (2005). Multimodal texts: What they are and how children use them. In J. Evans (Ed.), Litarcy moves on (pp. 13-29). Portsmouth, NH: Heinemann.

Bearne, E., \& Kress, G. (2001). Editorial: Multimodal communication. Reading, Literacy and Language, 35(3), 89-93. http://dx.doi.org/10.1111/1467-9345.00168

Coffin, C., Donohue, J., \& North, S. (2009). Representing the world. Exploring English Grammar (pp. 282-332). London: Routledge.

Cole, D. (2009, March 23). Climate change could harm penguins and polar bears.Retrieved December 19, 2012 from http://www.usnews.com/news/energy/articles/2009/03/23/climate-change-could-harm-penguins-andpolar-bears

Droga, L., \& Humphrey, S. (2003). Evaluating phenomena. Grammar and Meaning: An Introduction for Primary Teachers (pp. 64-79). Berry, NSW: Target Texts.

Goatly, A. (2002). Text and interpersonal meaning. Critical Reading and Writing: An Introductory Coursebook (pp. 83-116). London: Routledge.

Halliday, M. A. K. (1994). An introduction to functional grammar ( $2^{\text {nd }}$ ed.). London: Edward Arnold.

$\begin{aligned} & \text { Homeless } \\ & \text { http://adsoftheworld.com/media/print/wwf_homeless_penguin }\end{aligned}$
$\begin{aligned} & \text { Homeless Polar Bears } \quad \text { (n.d.). Retrieved December } \\ & \text { http://adsoftheworld.com/media/print/wwf_homeless_polar_bear }\end{aligned}$


Moore, T. (2010). The 'processes of learning: On the use of Halliday's transitivity in academic skills advising. In C. Coffin, T. Lillis, \& K. O’Halloran (Eds.), Applied Linguistics Methods: A Reader (pp. 52-71). London: Routledge.

Ravelli, L. (2000). Getting started with functional analysis of texts. In L. Unsworth (Ed.), Researching Language in Schools and Communities (pp. 27-64). London: Cassell.

Schleppegrell, M. (2004). Linguistic features of academic registers. The Language of Schooling (pp. 43-76). Mahwah, N.J.: Lawrence Erlbaum.

Stenglin, M., \&Iedema, R. (2001). How to analyse visual images: A guide for TESOL teachers. In A. Burns, \& C. Coffin (Eds.), Analysing English in a global context: A reader (pp. 194-205). London: Open University. 